\title{
Influence of Surface Oxidation of Nickel-Coated Carbon Fibre on Oxygen Evolution Reaction in Alkaline Solution
}

\author{
Tomasz Mikolajczyk*, Boguslaw Pierozynski \\ Department of Chemistry, Faculty of Environmental Management and Agriculture, University of \\ Warmia and Mazury in Olsztyn, Plac Lodzki 4, 10-727 Olsztyn, Poland \\ *E-mail: tomasz.mikolajczyk@uwm.edu.pl
}

doi: $10.20964 / 2017.12 .18$

Received: 12 September 2017 / Accepted: 21 October 2017 / Published: 12 November 2017

This work reports on oxygen evolution reaction (OER), studied at nickel-coated carbon fibre (NiCCF) electrodes. The OER was examined comparatively on non-oxidized and electrooxidized NiCCF 12K50 tow materials in $0.1 \mathrm{M} \mathrm{NaOH}$ solution for the potential range: $1600-1800 \mathrm{mV}$ vs. RHE. Electrochemical modification of NiCCF electrode results in significant facilitation of the OER kinetics, manifested through reduced, ac. impedance-derived values of charge-transfer resistance parameter and considerably modified Tafel polarization slopes.

Keywords: NiCCF; OER; Electrochemical impedance spectroscopy; NiOOH.

\section{FULL TEXT}

(C) 2017 The Authors. Published by ESG (www.electrochemsci.org). This article is an open access article distributed under the terms and conditions of the Creative Commons Attribution license (http://creativecommons.org/licenses/by/4.0/). 